\title{
Weissella ghanensis sp. nov., isolated from a Ghanaian cocoa fermentation
}

\author{
Katrien De Bruyne, ${ }^{1}$ Nicholas Camu, ${ }^{2}$ Karen Lefebvre, ${ }^{1}$ Luc De Vuyst ${ }^{2}$ \\ and Peter Vandamme ${ }^{1}$
}

Correspondence

Katrien De Bruyne

Katrien.DeBruyne@UGent.be

\author{
${ }^{1}$ Laboratory of Microbiology and BCCM/LMG Bacteria Collection, Ghent University, K. L. \\ Ledeganckstraat 35, B-9000 Ghent, Belgium \\ ${ }^{2}$ Research Group of Industrial Microbiology and Food Biotechnology (IMDO), Department of \\ Applied Biological Sciences and Engineering, Vrije Universiteit Brussel, Pleinlaan 2, B-1050 \\ Brussels, Belgium
}

\begin{abstract}
During a study on lactic acid bacteria (and their species diversity) in spontaneous heap fermentations of Ghanaian cocoa beans, two strains, designated $215^{\top}$ and $194 \mathrm{~B}$, were isolated. A phylogenetic analysis based on 16S rRNA gene sequences demonstrated that these strains represented a distinct lineage close to the genus Weissella and showing only $92.1 \% 16 \mathrm{~S}$ rRNA gene sequence similarity with respect to their closest neighbour, Weissella soli LMG $20113^{\top}$. Whole-cell protein electrophoresis, fluorescent amplified fragment length polymorphism fingerprinting of whole genomes and physiological and biochemical tests confirmed the unique taxonomic position of the two novel isolates. On the basis of the results of the morphological and biochemical tests and 16S rRNA gene sequence analysis, strains $215^{\top}$ and 194B represent the most peripheral lineage of the genus Weissella, for which we propose the name Weissella

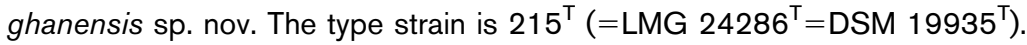

The genus Weissella was created by Collins et al. (1993), in the course of a phylogenetic analysis of some unknown Leuconostoc-like lactic acid bacteria, to accommodate five heterofermentative Lactobacillus species and a species formerly classified as Leuconostoc paramesenteroides. Novel species of the genus Weissella have mainly been isolated from fermented foods: Weissella hellenica strains were isolated from fermented sausages (Collins et al., 1993), Weissella kimchii (a later heterotypic synonym of Weissella cibaria) (Ennahar \& Cai, 2004) and Weissella koreensis strains were isolated from kimchi (Choi et al., 2002; Lee et al., 2002), and Weissella thailandensis strains were isolated from fermented fish (Tanasupawat et al., 2000). The exceptions are Weissella soli strains, which were isolated from soil (Magnusson et al., 2002), and some W. cibaria strains that were detected in both fermented food and clinical samples (Björkroth et al., 2002).

\footnotetext{
Abbreviations: FAFLP, fluorescent amplified fragment length polymorphism; RAPD, randomly amplified polymorphic DNA.

The GenBank/EMBL/DDBJ accession numbers for the 16S rRNA gene sequences of strain $215^{\top}$ and strain 194B are AM882997 and AM882998, respectively.

An extended neighbour-joining phylogenetic tree (based on 16S rRNA gene sequences) and whole-cell protein profiles for the novel strains, type strains of recognized Weissella species and other closely related taxa are available as supplementary figures with the online version of this paper.
}

The population dynamics of spontaneous heap fermentations of cocoa beans in Ghana during the main cropping season of 2005 (October-December) were studied by Camu et al. (2007). The levels of lactic acid bacteria species diversity of different fermentation heaps and different fermentation times were signalled by the relative intensities of bands obtained using a culture-independent technique, namely 16S rRNA gene sequence-based PCRdenaturing gradient gel electrophoresis. This analysis detected an unidentified bacterium that appeared in five of the seven heap fermentations studied, from the beginning of the fermentation up to $48 \mathrm{~h}$ after the start of the fermentation process. The $16 \mathrm{~S}$ rRNA gene sequence of this bacterium was determined. Only three isolates $\left(215^{\mathrm{T}}, 194 \mathrm{~B}\right.$ and 225$)$ that had $16 \mathrm{~S}$ rRNA gene sequences identical to that of the unidentified bacterium were obtained (and subsequently cultivated) from the same fermenting cocoa bean heap in New Tafo, Ghana (Camu et al., 2007). Isolate 225 lost viability during subsequent cultivation. To check clonality using randomly amplified polymorphic DNA (RAPD; Chen et al., 2001), DNA from each isolate was prepared by alkaline lysis (Coenye et al., 2002) and the DNA solutions were stored at $-20{ }^{\circ} \mathrm{C}$. Fingerprinting using RAPD was performed with primers RAPD-270 (5'-TGCGCGCGGG-3') and RAPD-272 (5' AGCGGGCCAA-3'), as described previously (Mahenthiralingam et al., 1996). Isolates $215^{\mathrm{T}}$ and $194 \mathrm{~B}$ were found to be non-clonal strains (data not shown). 
The taxonomic positions of strain $215^{\mathrm{T}}$ and strain $194 \mathrm{~B}$ were first investigated by means of $16 \mathrm{~S}$ rRNA gene sequence analysis, as described by Vancanneyt et al. (2004) but with the following modification: the PCRamplified 16S rRNA gene was purified using a NucleoFast 96 PCR Clean-up kit (Macherey-Nagel). Sequencing reactions were purified using a Montage SEQ96 Sequencing Reaction Clean-up kit (Millipore). Electrophoresis of sequence reaction products was performed by using an ABI Prism 3100 genetic analyser (Applied Biosystems). A BLAST search and phylogenetic analysis based on $16 \mathrm{~S}$ rRNA gene sequence similarity showed that strain $215^{\mathrm{T}}$ was related to members of the genus Weissella, the highest sequence similarity (92.1\%) being found with respect to $W$. soli LMG $20113^{\mathrm{T}}$. The $16 \mathrm{~S}$ rRNA gene sequences obtained (continuous stretches of $1541 \mathrm{bp}$ and $1538 \mathrm{bp}$ ) and sequences of the type strains from all species of the genus Weissella were aligned using CLUSTAL_X (version 1.81; Thompson et al., 1997) and clustered using the BioNumerics software package, version 5.10 (Applied Maths). The maximum-parsimony and maximum-likelihood tree-building methods revealed similar topologies to those obtained in a phylogenetic tree constructed using the neighbour-joining approach (Fig. 1), which was calculated using bootstrapping based on 200 replications. The neighbour-joining analysis revealed strain $215^{\mathrm{T}}$ as a distinct phylogenetic lineage close to the genus Weissella. A broader phylogenetic analysis including all of the phylogenetically closest neighbours of the genus Weissella, namely the genera Pediococcus, Oenococcus and Leuconostoc, is shown in Supplementary Fig. S1 (available in IJSEM Online). This analysis demonstrated that strains $215^{\mathrm{T}}$ and $194 \mathrm{~B}$ can be considered as representing the most peripheral branch of the genus Weissella. On the basis of the data from additional analyses described below, these strains were not assigned to a novel genus but were recognized as representing a novel species of the genus Weissella. This peripheral position could be the result of differences in the rate of evolution of strains $215^{\mathrm{T}}$ and 194B with respect to Weissella species. The large divergence in $16 \mathrm{~S}$ rRNA gene sequence $(>7.4 \%)$ demonstrates unambiguously that the two strains represent a novel species that is closely related to the recognized species of the genus Weissella.

SDS-PAGE of whole-cell proteins and fluorescent amplified fragment length polymorphism (FAFLP) techniques were used to characterize these novel bacteria in more detail and were performed as described by Pot et al. (1994) and Franz et al. (2006), respectively. Protein profiles for Weissella reference strains were taken from Björkroth et al. (2002). To complete the protein profile reference data for all Weissella species, protein profiles for W. koreensis LMG $21853^{\mathrm{T}}$ and $W$. soli LMG $20113^{\mathrm{T}}$ were generated. The whole-cell protein profiles of strains $215^{\mathrm{T}}$ and $194 \mathrm{~B}$ formed a distinct branch within the dendrogram obtained (see Supplementary Fig. S2, available in IJSEM Online). Similarly, reference FAFLP data for all type strains were supplemented with data for $W$. koreensis LMG $21853^{\mathrm{T}}, W$. soli LMG 20113 ${ }^{\mathrm{T}}$, W. thailandensis LMG $19821^{\mathrm{T}}$ and Weissella kandleri LMG $18979^{\mathrm{T}}$. The unique taxonomic position of strains $215^{\mathrm{T}}$ and $194 \mathrm{~B}$ was again confirmed by numerical analysis of the FAFLP fingerprints (Fig. 2).

The DNA G + C content of strain $215^{\mathrm{T}}$ was determined, as described by Mesbah et al. (1989), using a Waters Breeze HPLC system and an XBridge Shield RP18 column. The solvent used was $0.02 \mathrm{M} \mathrm{NH}_{4} \mathrm{H}_{2} \mathrm{PO}_{4}(\mathrm{pH} 4.0)$ with $1.5 \%$ $(\mathrm{v} / \mathrm{v})$ acetonitrile. Escherichia coli LMG 2093 DNA was used as the control and non-methylated lambda phage DNA (Sigma) was used as the calibration reference. The DNA $\mathrm{G}+\mathrm{C}$ content of strain $215^{\mathrm{T}}$ was found to be $40.0 \mathrm{~mol} \%$, which falls within the range for the genus Weissella (37$47 \mathrm{~mol} \%$; Collins et al., 1993).

Cell and colony morphology were investigated after growth on MRS agar ( $\mathrm{pH} 5.4$, Oxoid) and $48 \mathrm{~h}$ aerobic incubation

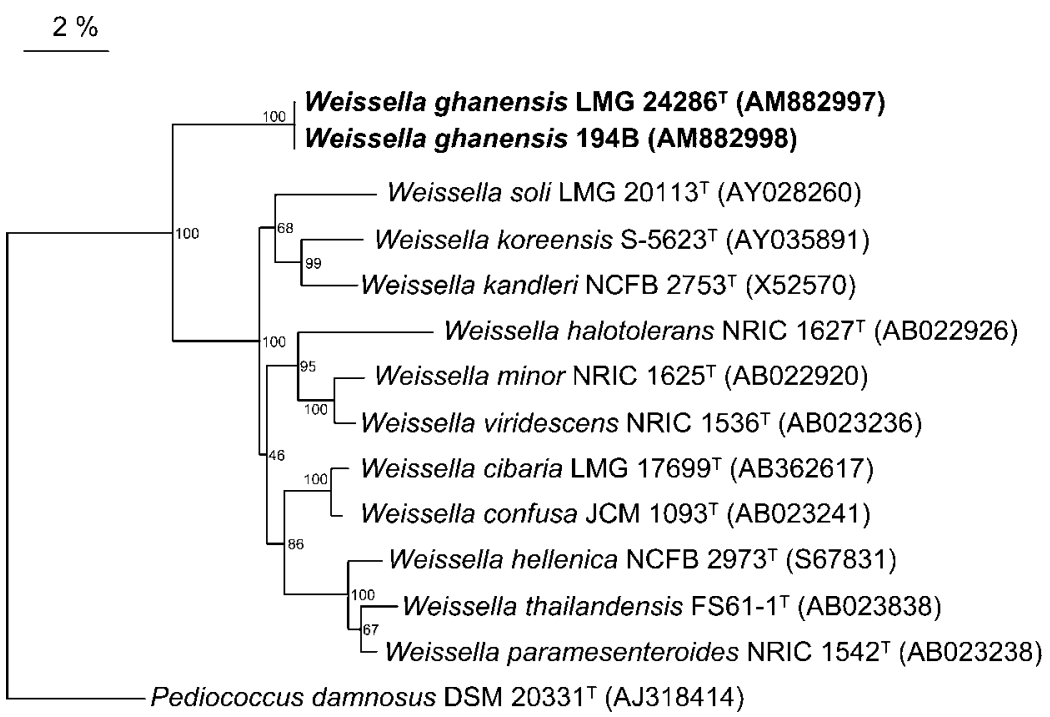

Fig. 1. Phylogenetic neighbour-joining tree, based on 16S rRNA gene sequences, showing the phylogenetic relationships of strains $215^{\top}$ and $194 \mathrm{~B}$ with respect to members of the genus Weissella. Bootstrap percentages (based on 200 replications) are shown at branch points. Pediococcus damnosus DSM $20331^{\top}$ was used as the outgroup. Bar, $2 \%$ sequence divergence. 


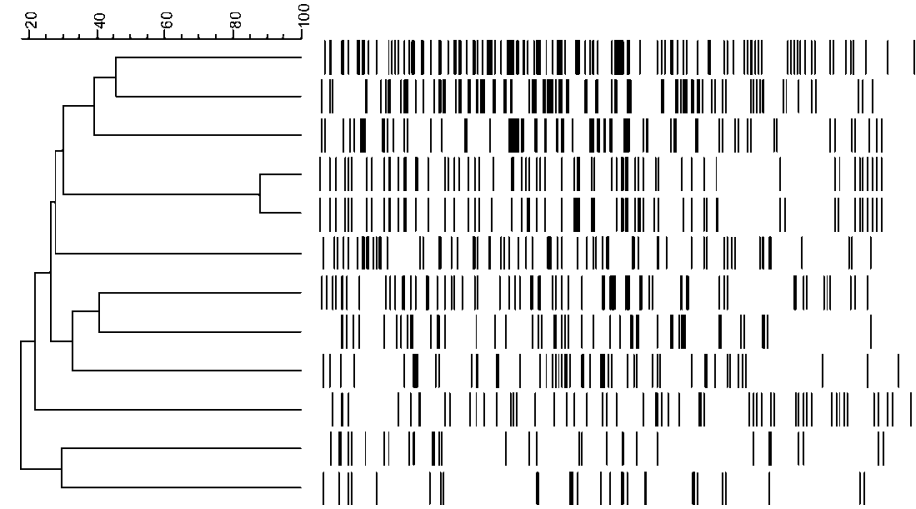

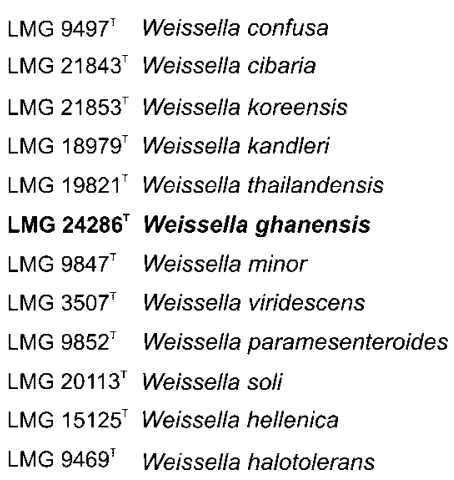

LMG $9497^{\top} \quad$ Weissella confusa

LMG $21843^{\top}$ Weissella cibaria

LMG $21853^{\top}$ Weissella koreensis

LMG $18979^{\top}$ Weissella kandleri

LMG $19821^{\top}$ Weissella thailandensis

LMG 24286 ${ }^{\top}$ Weissella ghanensis

Weissella minor

LMG $3507^{\top} \quad$ Weissella viridescens

LMG $9852^{\top} \quad$ Weissella paramesenteroides

LMG 20113' Weissella sol

LMG 9469' Weissella halotolerans

Fig. 2. FAFLP patterns and dendrogram based on UPGMA linkage of Dice coefficients of strains $215^{\top}$ and $194 \mathrm{~B}$ and reference strains from all of the recognized species of the genus Weissella.

at $28{ }^{\circ} \mathrm{C}$, unless stated otherwise. Standard biochemical tests and growth experiments were determined in MRS broth ( $\mathrm{pH}$ 5.4, Oxoid). All tests were performed in triplicate, unless stated otherwise. Growth was tested at 4, $10,15,37$ and $45{ }^{\circ} \mathrm{C}$, in the presence of 5, 6, 7 and $8 \%$ $\mathrm{NaCl}$ and at $\mathrm{pH} 3.9$ at $37^{\circ} \mathrm{C}$. The production of gas from $2 \%$ glucose and $2 \%$ gluconate in modified MRS broth ( $\mathrm{pH}$ 5.4, without the addition of triammonium citrate) was investigated using Durham tubes. Arginine hydrolysis was evaluated in a medium containing $0.5 \%$ tryptone, $0.5 \%$ yeast extract, $0.3 \%$ L-arginine, $0.05 \%$ glucose, $0.2 \%$ $\mathrm{K}_{2} \mathrm{HPO}_{4}$ (pH 7.0), with methyl orange as an indicator. Metabolites from glucose were determined in duplicate by means of HPLC (Waters apparatus). The proportions of Dand L-lactate were determined enzymically (R-Biopharm). Carbohydrate-fermentation tests were performed using the API 50 CHL system (bioMérieux). Other physiological and biochemical characteristics were determined using the API 20E system (bioMérieux); both strips were analysed in duplicate, according to the manufacturer's instructions. For the detection of glucose metabolites and D/L lactate isomers, strains were grown for $96 \mathrm{~h}$ at $30{ }^{\circ} \mathrm{C}$ in MRS broth ( $\mathrm{pH}$ 5.4, Oxoid). The results of this characterization are given in the species description.

In spite of the peripheral position of strains $215^{\mathrm{T}}$ and 194B in the phylogenetic tree based on 16S rRNA gene sequences (Fig. 1), the biochemical characteristics observed for the two strains (i.e. their cell and colony morphology, motility, catalase activity, heterofermentative metabolism, arginine hydrolysis and growth temperatures) and their DNA G + C content conformed to the expected profile of members of the genus Weissella (Collins et al., 1993). The two novel strains could be clearly distinguished from homofermentative strains (e.g. pediococci) by the formation of gas from carbohydrates. The ability of strains $215^{\mathrm{T}}$ and 194 to hydrolyse arginine and to form DL-lactate served to differentiate them from strains of the genus Leuconostoc. The novel isolates could be differentiated from recognized
Weissella species on the basis of phylogeny, whole-cell protein profiles, AFLP results and biochemical data (Table 1). Thus, strains $215^{\mathrm{T}}$ and 194 represent a novel species of the genus Weissella, for which the name Weissella ghanensis sp. nov. is proposed.

\section{Description of Weissella ghanensis sp. nov.}

Weissella ghanensis (gha.nen'sis. N.L. fem. adj. ghanensis pertaining to Ghana).

Cells are Gram-positive, catalase-negative and facultatively anaerobic. They do not form spores. Gliding motility is not observed. Cells are small rods $(1.0 \mu \mathrm{m}$ wide and $2.0-4.0 \mu \mathrm{m}$ long) and appear singly, in pairs or in short chains. Colonies are beige, opaque, smooth, circular or irregular with low convex elevation and entire margins and are $1.5-2.0 \mathrm{~mm}$ in diameter. Growth is obtained at $15-37^{\circ} \mathrm{C}$. No growth is observed in MRS broth supplemented with $5 \% \mathrm{NaCl}$. For strain $215^{\mathrm{T}}$, lactic acid (D/L, $\left.90: 10\right)$, acetic acid, ethanol and gas formation are detected after growth on glucose, indicating the heterofermentative nature of this strain. Strain 194B produces different end metabolites. Both lactic acid and acetic acid are detected as end products of glucose metabolism. Mainly D-lactate (D/L, 95:5) is produced and no gas production is observed. Strain $215^{\mathrm{T}}$ and strain 194B both produce slime from sucrose and are able to hydrolyse arginine. Acid is produced from glucose, fructose, mannose, $\mathrm{N}$-acetylglucosamine, amygdalin, arbutin, aesculin, salicin, cellobiose, maltose, trehalose and gentiobiose, but not from glycerol, erythritol, D-arabinose, L-arabinose, ribose, Dxylose, L-xylose, adonitol, methyl $\beta$-D-xylopyranoside, galactose, sorbose, rhamnose, dulcitol, inositol, mannitol, sorbitol, methyl $\alpha$-D-mannopyranoside, methyl $\alpha$-D-glucopyranoside, lactose, melibiose, inulin, melezitose, raffinose, starch, glycogen, xylitol, D-turanose, D-lyxose, D-tagatose, Dfucose, L-fucose, D-arabitol, L-arabitol, gluconate, 2-ketogluconate or 5 -ketogluconate. Strain $215^{\mathrm{T}}$ produces acid from sucrose; strain 194B does not produce acid from sucrose. 
Table 1. Differential characteristics of Weissella ghanensis sp. nov. and other species of the genus Weissella

Taxa: 1 , strains $215^{\mathrm{T}}$ and 194B; 2, W. halotolerans; 3, W. minor; 4, W. viridescens; 5, W. soli; 6, W. kandleri; 7, W. koreensis; 8, W. cibaria; 9, W. confusa; 10, W. thailandensis; 11, W. hellenica; 12, W. paramesenteroides. Data partially adapted from Collins et al. (1993), Tanasupawat et al. (2000), Björkroth et al. (2002), Choi et al. (2002), Lee et al. (2002), Magnusson et al. (2002) and Ennahar \& Cai (2004). +, Positive for at least $90 \%$ of the strains; -, negative for at least $90 \%$ of the strains; d, positive for $11-89 \%$ of strains; NT, not tested.

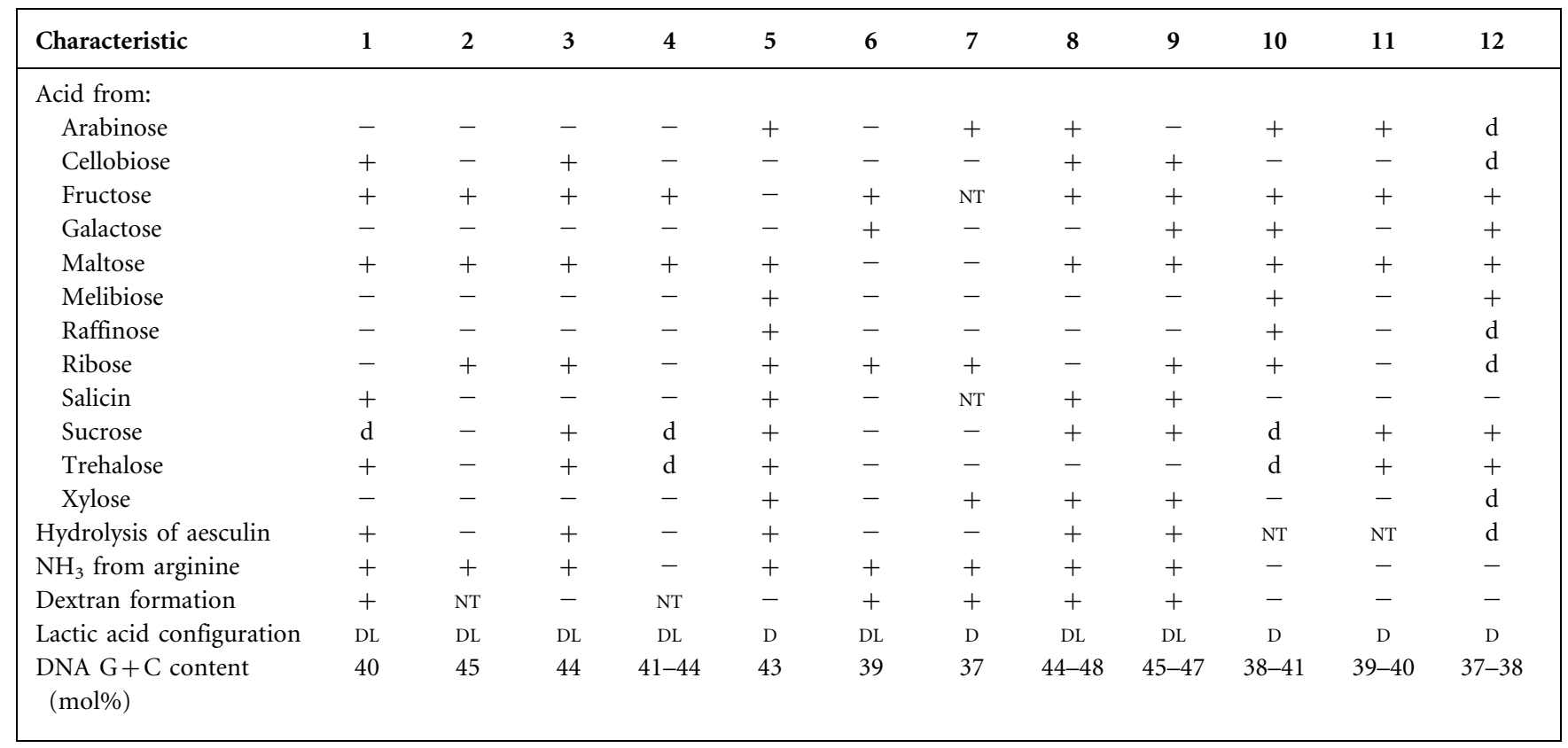

The type strain, $215^{\mathrm{T}}\left(=\mathrm{LMG} 24286^{\mathrm{T}}=\mathrm{DSM} 19935^{\mathrm{T}}\right)$, was isolated from Ghanaian cocoa bean heaps undergoing fermentation. The DNA G $+\mathrm{C}$ content of the type strain is $40.0 \mathrm{~mol} \%$. The two available strains $\left(215^{\mathrm{T}}\right.$ and $\left.194 \mathrm{~B}\right)$ both originated from the same cocoa bean heap undergoing fermentation in New Tafo, Ghana. However, Camu et al. (2007) detected this organism in five out of seven spontaneous heap fermentations of cocoa beans studied, indicating that this species is common in Ghanaian cocoa bean heaps that are undergoing fermentation.

\section{Acknowledgements}

This work was supported by the Federal Research Policy [Action for the Promotion of and Co-operation with the Belgian Co-ordinated Collections of Micro-organisms (C3/00/17)], the Research Council of the Vrije Universiteit Brussel (GOA project), the Institute for the Promotion of Innovation through Science and Technology in Flanders (IWT project 040043) and Barry Callebaut NV. The cooperation of the Ghanaian Cocoa Producers' Alliance (COCOBOD; Accra, Ghana) and the Cocoa Research Institute of Ghana are greatly appreciated. Approval was obtained by COCOBOD to cooperate with local farmers. The authors wish to acknowledge Tom De Winter and Ann Van Schoor for technical support.

\section{References}

Björkroth, K. J., Schillinger, U., Geisen, R., Weiss, N., Hoste, B., Holzapfel, W. H., Korkeala, H. J. \& Vandamme, P. (2002). Taxonomic study of Weissella confusa and description of Weissella cibaria sp. nov., detected in food and clinical samples. Int J Syst Evol Microbiol 52, 141-148.

Camu, N., De Winter, T., Verbrugghe, K., Cleenwerck, I., Takrama, J. S., Vancanneyt, M. \& De Vuyst, L. (2007). Dynamics and biodiversity of lactic acid bacteria and acetic acid bacteria populations involved in spontaneous heap fermentations of cocoa beans in Ghana. Appl Environ Microbiol 73, 1809-1824.

Chen, J. S., Witzmann, K. A., Spilker, T., Fink, R. J. \& LiPuma, J. J. (2001). Endemicity and inter-city spread of Burkholderia cepacia genomovar III in cystic fibrosis. J Pediatr 139, 643-649.

Choi, H. J., Cheigh, C. I., Kim, S. B., Lee, J. C., Lee, D. W., Choi, S. W., Park, J. M. \& Pyun, Y. R. (2002). Weissella kimchii sp. nov., a novel lactic acid bacterium from kimchi. Int J Syst Evol Microbiol 52, 507-511.

Coenye, T., Spilker, T., Martin, A. \& LiPuma, J. J. (2002). Comparative assessment of genotyping methods for epidemiologic study of Burkholderia cepacia genomovar III. J Clin Microbiol 40, 3300-3307.

Collins, M. D., Samelis, J., Metaxopoulos, J. \& Wallbanks, S. (1993). Taxonomic studies on some leuconostoc-like organisms from fermented sausages: description of a new genus Weissella for the Leuconostoc paramesenteroides group of species. J Appl Bacteriol 75, 595-603.

Ennahar, S. \& Cai, Y. (2004). Genetic evidence that Weissella kimchii Choi et al. 2002 is a later heterotypic synonym of Weissella cibaria Björkroth et al. 2002. Int J Syst Evol Microbiol 54, 463-465.

Franz, C. M. A. P., Vancanneyt, M., Vandemeulebroecke, K., De Wachter, M., Cleenwerck, I., Hoste, B., Schillinger, U., Holzapfel, W. H. \& Swings, J. (2006). Pediococcus stilesii sp. nov., isolated from maize grains. Int J Syst Evol Microbiol 56, 329-333.

Lee, J. S., Lee, K. C., Ahn, J. S., Mheen, T. I., Pyun, Y. R. \& Park, Y. H. (2002). Weissella koreensis sp. nov., isolated from kimchi. Int J Syst Evol Microbiol 52, 1257-1261. 
Magnusson, J., Jonsson, H., Schnurer, J. \& Roos, S. (2002). Weissella soli sp. nov., a lactic acid bacterium isolated from soil. Int J Syst Evol Microbiol 52, 831-834.

Mahenthiralingam, E., Campbell, M. E., Henry, D. A. \& Speert, D. P. (1996). Epidemiology of Burkholderia cepacia infection in patients with cystic fibrosis: analysis by randomly amplified polymorphic DNA fingerprinting. J Clin Microbiol 34, 2914-2920.

Mesbah, M., Premachandran, U. \& Whitman, W. B. (1989). Precise measurement of the $\mathrm{G}+\mathrm{C}$ content of deoxyribonucleic acid by highperformance liquid chromatography. Int J Syst Bacteriol 39, 159-167.

Pot, B., Vandamme, P. \& Kersters, K. (1994). Analysis of electrophoretic whole-organism protein fingerprints. In Chemical Methods in Prokaryotic Systematics, pp. 493-521. Edited by M. Goodfellow \& A. G. O’Donnell. Chichester, UK: Wiley.
Tanasupawat, S., Shida, O., Okada, S. \& Komagata, K. (2000). Lactobacillus acidipiscis sp. nov. and Weissella thailandensis sp. nov., isolated from fermented fish in Thailand. Int J Syst Evol Microbiol 50, 1479-1485.

Thompson, J. D., Gibson, T. J., Plewniak, F., Jeanmougin, F. \& Higgins, D. G. (1997). The CLUSTAL_X windows interface: flexible strategies for multiple sequence alignment aided by quality analysis tools. Nucleic Acids Res 25, 4876-4882.

Vancanneyt, M., Mengaud, J., Cleenwerck, I., Vanhonacker, K., Hoste, B., Dawyndt, P., Degivry, M. C., Ringuet, D., Janssens, D. \& Swings, J. (2004). Reclassification of Lactobacillus kefirgranum Takizawa et al. 1994 as Lactobacillus kefiranofaciens subsp. kefirgranum subsp. nov. and emended description of L. kefiranofaciens Fujisawa et al. 1988. Int J Syst Evol Microbiol 54, 551-556. 